\title{
PRESERVATION OF THE HYDRAULIC HERITAGE IN LANDSCAPES UNDER PERMANENT WATER STRESS: NEW APPROACH TO UTILITY AND SUSTAINABILITY CRITERIA
}

\author{
MARÍA MAGDALENA MARTÍNEZ ALMIRA* \\ University of Alicante, Spain
}

\begin{abstract}
The purpose of this paper is to examine the legal sources that allow the organization of the space in areas of water scarcity and affected by weather variations in the Mediterranean basin, offering a comparative and comprehensive analysis of the legal criteria widespread under influence for the eastern part of the Mediterranean. The study approaches the subject from a legal historical perspective, reference to the rules applied in different environments and divisive uses from the legal vestiges preserved as memorial sites, legal sources and customs. A map of sources governed by criteria of the usefulness, sustainability and general consensus. These are all factors key for the coordinated approach in the establishment of a network of hydraulic structures and gadgets in the urban and rural landscape. This lecture makes its own thoughtful contribution to an important ongoing debate to the water protection and management safeguarding hydraulic heritage. In conclusion, the analysis considers specific current situations, policies and institutions that provide solutions to daily problems in public and private spaces combining modernization that are considered such proposals for the future of water management.

Keywords: water, distribution, sustainability, heritage, tradition, law, al-Andalus.
\end{abstract}

\section{INTRODUCTION}

Over the centuries, the territories in which the irrigation techniques of eastern origin were applied - and more precisely as Islam expanded across the Mediterranean - also became recipients of a water law with its own characteristics. Based on its particular structure and hierarchy, Islamic law addresses the right to water use in a transversal manner, at least in what regards the mu'àmalāt or Islamic jurisprudence, related to acts involving interaction and exchange among people. The commitment of users, both at the level of consumption for the intake and regarding production and industry - irrigators or manufacturers - constitutes an undeniable fact, pursuant to a legal framework widely accepted from time immemorial.

\section{LAND TENURE MODES AND THEIR EFFECTS ON ACCESS TO WATER: RULES FOR ACTION THROUGH THE DOCTRINE IN AL-ANDALUS}

From a conceptual point of view, the regime of water is defined as ahkām al-mi'ah and not as haqq al-mi'ah. This nuance becomes especially interesting when it comes to exercising the right on water. The word ahkäm derives from the root $\mathrm{h}-\mathrm{k}-\mathrm{m}$ and has as its meanings that of ruling or passing a judgment or to give a legal opinion; hakma [1, p. 161] means being wise, but also learned and sensible. And tahkim is the arbitration or the act of arbitrating a consensus-based solution between several individuals. Instead, the root $h-q-q[1, \mathrm{p}$. 165] expresses truth, law, duty; $h \bar{a} q q$ defines what is perfect, and haqqāni conveys the meaning of legitimate and fair. The concept defining the area of law which regulates water use and distribution refers back to the term 'arbitration' as the legitimate way to settle any issues

*ORCID: https://orcid.org/0000-0003-2721-8029 


\title{
WATER GOVERNANCE IN THE SMART CITY
}

\author{
ANDRÉS MOLINA-GIMÉNEZ \\ Professor of Administrative Law, University of Alicante, Spain
}

\begin{abstract}
A smart city is one that solves its main problems efficiently, relying on new technologies. Its policies should focus on achieving economic efficiency, environmental sustainability and social development. These objectives require establishing a model of intelligent governance, with democratic functioning, public participation, transparency and electronic administration. Urban water management, under these parameters, need to focus efforts on efficient supply, reduction of losses, progressive tariffs and efforts in education, sanitation and integral purification of wastewater. It must also promote the reuse of reclaimed water. In addition, it is necessary to select a management system that suits well the particular conditions of the city, guaranteeing a transparent operation of all the actors involved. In short, smart cities must incorporate technology for the benefit of environmental and social sustainability. In the water sector, the smart city must equip itself with instruments to ensure a universal, continuous, regular and high-quality public service. An effective management system, where public-private collaboration is developed, supported by suitable regulatory instruments, is of the greatest interest. The purification of urban wastewater, and its subsequent reuse, are fundamental tools of the circular economy, and lead to more environmentally sustainable cities. There are significant possibilities for reuse of wastewater for the city's own uses, thereby reducing pressures on pure water sources. On the other hand, the smart city's water management system should be based on the principles of transparency and good governance. In sum, the relations between the smart city principles and water management shall be addressed in the study.
\end{abstract}

Keywords: smart city, water, governance, efficiency, law, public services, technology, transparency, accountability.

\section{INTRODUCTION}

In 2012, the European Commission launched a specific initiative for the development of smart cities called "Smart Cities and Communities - European Partnership for Innovation" [1]. According to the European Parliament [2], smart cities can be identified and classified according to six main axes or dimensions. Smart governance is one of them. In the report "Mapping Smart cities in the EU", prepared by the European Parliament in 2014 [2], it is stated that a city can be considered "smart city" providing it has at least one initiative in the area of "Smart governance". A city should also be defined as "smart" as long as rational management of natural resources and infrastructures, through a participatory government, contribute to sustainable economic development and improve the quality of life [3].

The European Union has a strong financial commitment for the development of initiatives that allow "intelligent growth" of the territories within the EU 2020 strategy. This process started with the Seventh Framework Program (2007-2013). The European Regional Development Fund (ERDF) is also appropriate for the promotion of smart cities. In Spain, the Intelligent Growth Operating Program 2014-2020 has to be highlighted. As a result of this Program, in line with the Digital Agenda for Spain, financial aid has been offered in order to promote the use of ICT for the development of cities and territory.

The "Smart" concept is not limited to technological improvements, but to all actions, data collection and information processing, which allow better decision making to public managers, in terms of economic savings and environmental sustainability. Information and communication technologies, as well as the application of the best available techniques, are decisive for an intelligent water management (smart metering, up-to-date information on on- 
line consumption, network sensorisation, geographic information systems, early warning to regulate the flow of the rivers, water quality control, water reuse technologies, etc.).

The legal implications of the "smart city" model are fundamentally focused on the following areas: good governance, transparency and accountability, and e-administration, efficient and cost-effective management in both public management models and publicprivate partnership models, and "smart" public procurement.

The relationship between water governance and the concept of "smart city" must be observed from the perspective of environmental sustainability and the principles of the circular economy. Sustainability presents at least three dimensions: social, as long as citizens are directly concerned by environmental dynamics; the ecological one, providing the use of natural resources must be compatible with its preservation; and economic, given that the protection of the environment must be compatible with economic growth, and a balance between both perspectives must be achieved. Such a balance leads to the objectives of the so-called circular economy. No doubt that circular economy is more sustainable than the traditional linear economic system [4].

The intelligent management of the water cycle must be extended to the four phases in which it is composed: high water networks (between the catchment and the municipal water works), low water networks (urban networks), sanitation and wastewater treatment, and wastewater reuse. In this paper we will analyse the main instruments that can favour intelligent water management in each of these phases, from the legal and governance perspective.

\section{HIGH WATER NETWORKS}

The agents responsible for an intelligent management of water are diverse in this phase, as a result of the overlapping of competence areas that influence water management. A number of authorities and stakeholders are involved in water management from the catchment area to the deposit of purified water at the head of urban networks. Environmental competences, water management and protection competences, as well as competences on infrastructures, among others, are concerned in this stage.

In Spain, the River Basin Authorities, which are decentralized branches of the State, are responsible for the execution of large infrastructures (in collaboration with other agencies and state entities), as well as for river basin planning, and for the allocation of rights and the protection of the quality of water bodies. The regional authorities assume competences in environmental matters, wastewater treatment, and the management of supra-municipal water networks and infrastructures. Finally, municipal authorities and associative public bodies share some of the regional responsibilities and are responsible for managing urban water networks.

An intelligent water management should assure the accurate conservation of good quality status of all the water bodies, either surface waters or groundwater. A good management of networks and deposits, with application of the best technological solutions, must be secured. The key factor is to achieve adequate coordination between all the authorities and stakeholders involved. This coordination is sometimes achieved through the creation of public entities of an associative nature, where different entities with overlapping competencies collaborate. A good example in Spain is the Marina Baja Water Consortium (CAMB), which integrates in a single entity the River Basin Authority, the municipalities of the supplied area, and the Provincial Administration.

This institution makes agreements with communities of irrigators for the delivery of high quality water flows, which were granted in the $70 \mathrm{~s}$ as water concessions, in exchange of reclaimed water from the treatment plants in the area. In sum, clean spring water is exchanged 
for reclaimed water through contracts, without altering the pre-existing concessions. This collaborative model is a clear example of intelligent water management, and clearly maximizes environmental sustainability. The reuse of wastewater by the farmers moves away from the postulates of the linear economy [5], [6].

A key factor for an intelligent management of water in this phase is the optimization of water resources. The water available for urban supply can be of different origin, and in turn, can present different cost structures and environmental externalities. The water resource that presents lower costs is usually groundwater, but the overexploitation of aquifers can make its exploitation unviable in environmental terms, even reaching its depletion or salinization due to see intrusion. Surface resources are also cost-effective, but it must be taken into account that their quality can be sometimes poor. In other cases, such resources must be transported from other basins. Both situations can lead to higher costs and in the second case, can create significant territorial tensions and political discrepancies. Sea desalinated water is a sound option for coastal municipalities, but producing it has high costs due to the energy inputs.

In areas subject to water stress, the best solution is to combine all available resources to achieve affordable costs and environmentally sustainable management. In this sense, there is an experience of great interest in Spain, which also has a broad historical trajectory, the Mancomunidad de Canales del Taibilla (MCT). This State Agency manages high water networks that give water supply to approximately two million people in the Provinces of Alicante and Murcia (Southeast coast of Spain). The Agency works in an area with structural water deficit and growing demands. The greatest interest of this institution is that it guarantees urban supply thanks to flexible management of all available water sources, which include: groundwater, surface water, water transferred from other River Basins, and desalinated seawater [7].

In Fig. 1 the average volumes which are consumed, and their nature, are shown. Figures vary each year due to the availability of each type of source and the costs. The intelligent management of all the sources ensures water supply while minimizing costs and maximizing the environmental objectives.

As the Fig. 1 clearly indicates, the relevance of desalinated seawater has been growing in the last few years, providing surface water and groundwater availability has dramatically decreased in the area.

\section{LOW WATER NETWORKS}

This particular stage in water supply management is carried out from the municipal deposits, which are situated at the head of the distribution network and ending up at the consumer's tap. Technological innovations are more visible at this phase. Recent technologies applied to network management, pressure control, leak detection, as well as innovations in metering, among other aspects, strongly improve the network efficiency, allowing lower fluid losses, greater energy savings, better customer support and ultimately, fewer waste of water. Investing in water infrastructure ensures high quality water services and adopting innovative technologies for the reduction of leakages is essential for that purpose.

There are a number of governance measures and legal instruments that can be useful in order to achieve high quality water supply. Low water network management is a natural monopoly, so competition can hardly operate. Networks cannot be sectorized or segregated, and therefore, their management should normally be carried out by a single operator. The legal framework differs substantially from one country to another. In Spain, the legislator chose to declare this activity as a public service, and therefore, as a publicly owned sector. Companies can only participate as contractors in case the municipality decides to contract out the activity. 


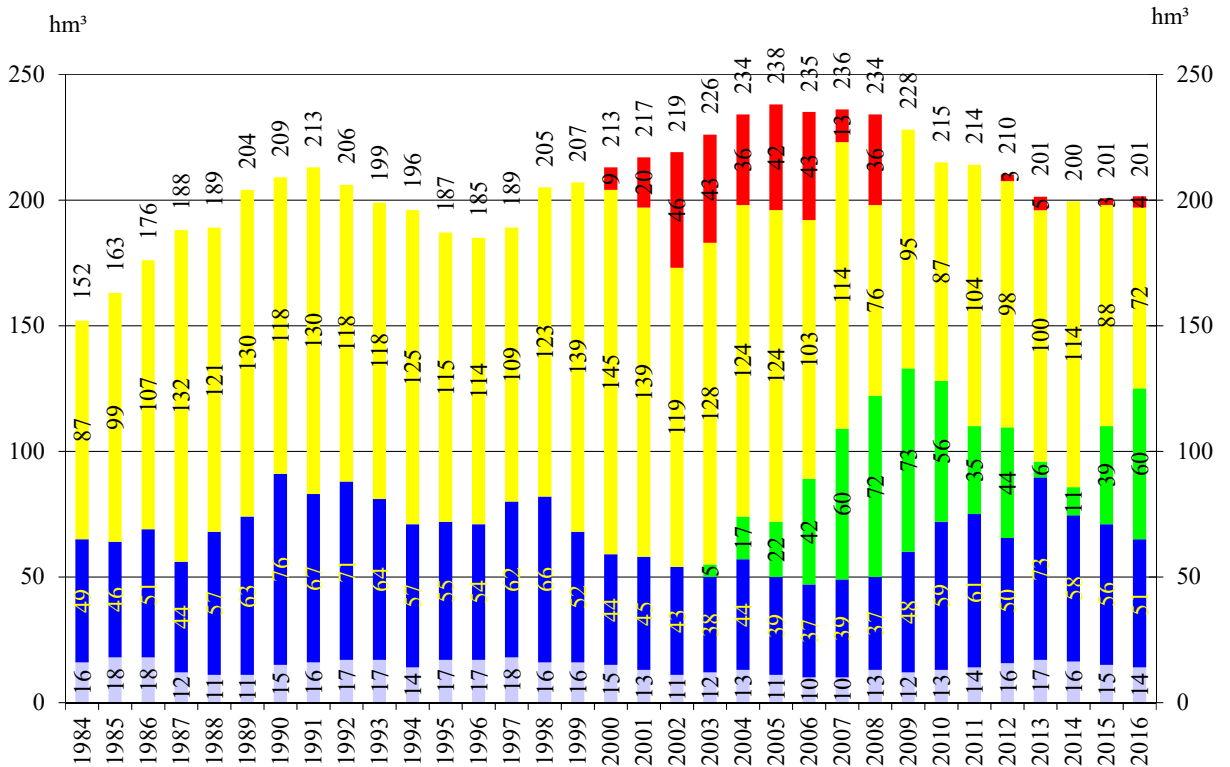

Groundwater $\square$ Surface water $\square$ Desalination Interbasin transfers $\square$ Groundwater, extra contributions

Figure 1: Pool of water sources in MCT high water networks system, Spain. (Source: MCT and own elaboration.)

In the British case, by contrast, the privatization and liberalization of water supply was adopted in the 1980s, though remaining under public control [8]. In any case, the public administration is always present in the activity, either as a manager or just as a regulator.

In case the Administration decides to hire a contractor, operating conditions must be established so to ensure the water company meets the public interest goals. The set of conditions of the public tender should demand the contractor investments and commitments aiming to improve network technologies, as well as investing in research, development and innovation. In sum, responsible authorities must ensure that municipal by-laws and contractual documents clearly define the rights and obligations of both, the private water company and the consumers, as well as the commitments assumed by the contractor in order to achieve cost-effective and sustainable water management.

Access to drinking water supply is widely achieved in the European Union. However, there problems with access to water in vulnerable groups are still present. ECI Right2Water, the most relevant initiative for participatory democracy in Europe, on the implementation of the human right to water and sanitation, has clearly stablished that accessing safe drinking water and sanitation is essential for life, human dignity, and to achieve an adequate standard of living. In this regard, the introduction of a new article in the Directive 98/83/EC, on the quality of water intended for human consumption, is currently being considered. The new legal framework would require Member States to assess the proportion of the population without proper access to drinking water, to inform these people about their right to get access to this service, and to encourage consumption of tap water in public buildings and restaurants. 
Member States will also be required to take all necessary measures to ensure full access to safe drinking water for groups of vulnerable people. These measures are essential for the development of the smart city, and innovative technologies applied to water management, as well as intelligent governance measures, are essential to achieve these goals.

It is also relevant to establish smart water pricing, which allows the user to make decisions for more responsible consumption. It is important the consumer knows that water has a value and a price, so he or she must act accordingly and responsibly. Getting immediate access to data related to consumption, through the application of innovative technologies, would help achieve a more sustainable use. In sum, smart water pricing is essential to induce people to make sustainable water use.

\section{WASTEWATER TREATMENT AND REUSE}

The urban cycle of water ends with the purification of raw sewage. Authorities are responsible to eliminate the pollutants that have been added to water after consumer's use. The predominant pollution of households is organic, but more serious pollutants can be added to water whereas small and medium industries are usually connected to urban networks. Wastewater treatment is a requirement for all the Member States according to the Council Directive 91/271/ EEC, concerning urban waste-water treatment. In accordance with this regulation, effluents from sewage treatment plants must secure a minimum quality so that they become compatible with maintaining good quality status of water bodies. In order to achieve this goal, the application of primary and secondary treatments is normally enough.

The smart city, however, must go beyond, so that these effluents do not necessarily end up in water courses of the sea, as long as at least part of them can be reused for different purposes: irrigation of public and private gardens, street cleaning, and many others. There are even some global experiences of using these resources for human consumption, although most legal systems do not allow this type of use. In theory, the application of tertiary treatments, namely ultrafiltration and reverse osmosis, can reach optimum water quality for human consumption, but there is still some reluctance to accept this possibility. However, it must be highlighted that indirect reuse of these resources is often done when treated wastewater is collected, after its dilution in the river course, below the pouring points. Such resources, properly treated, are therefore commonly used for human consumption when taken from the river. This indirect reuse has no legal concerns others than meeting the standards and quality conditions for drinking water.

Wastewater reuse avoids the deterioration of water bodies. It also generates a new economic activity, with qualified jobs. On the other hand, it is consistent with the postulates of the circular economy. In situations of water scarcity, reclaimed water is a factor that reduces the demand for natural sources, and as a result, it makes urban water supply system more sustainable.

Reclaimed water has enormous potential in the urban context, although the farming sector is still the one that most demands these resources. In the following table it is shown the important margin for using reclaimed water for urban purposes that still exists in the province of Alicante, considering that this Province, which is located in one of the driest areas of Spain, is one of the territories with highest wastewater reuse in Europe.

The greatest potential for wastewater reuse is found in the effluents that are poured to the sea, since the discharges to river courses are in many cases reused downstream (indirect reuse). The direct reuse of such effluents could therefore hamper access to water for municipalities located downstream, as well as harm farmers who were granted concessions for using surface water by the River Basin Agency. 


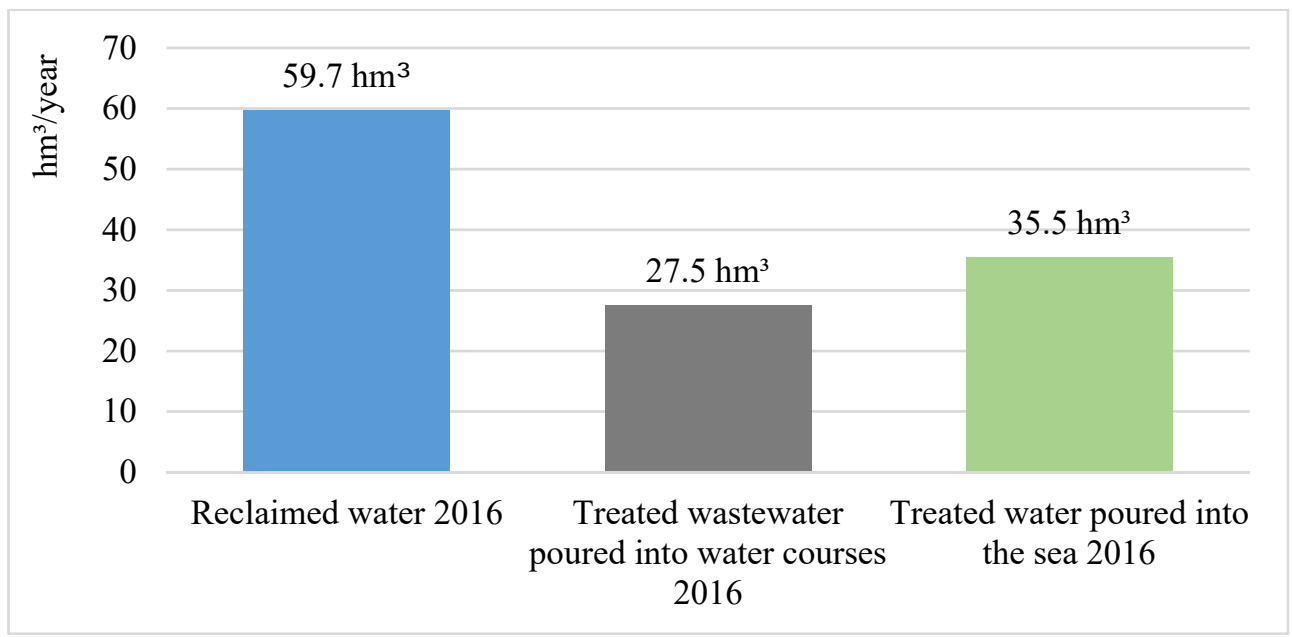

Figure 2: Destination of purified water in the province of Alicante, Spain. (Source: Prats, 2018 [9].)

\section{STORM WATER}

Rain water contains a high polluting load, sometimes even higher than household wastewater, since it collects the dirt that is deposited on the public roads. Such polluting load is particularly high at the first moment when precipitation occurs. Bringing these effluents to municipal wastewater treatment plants is particularly complex, since rainfall occurs at a specific time and with variable intensity. Even if part of these flows can be transported to the plant, the total flow, including wastewater can exceed the treatment capacity. Logically, the treatment plants are designed for a specific flow volume and must not be oversized.

There are technological solutions that prevent, at least part of these waters, from ending up intensely contaminating rivers or the sea. These include sustainable urban drainage systems (SUDs), which also favour the control of floods [10], [11]. There are also solutions such as the construction of storm ponds, which allow collecting the first flows, deposit them, and then raise them to the treatment plant. Another option is represented by the construction of outdoor deposits, which also create recreational and leisure spaces. This is the case of flooding park in the city of Alicante, Spain [12]. These kinds of solutions can help making cities climate change resilient.

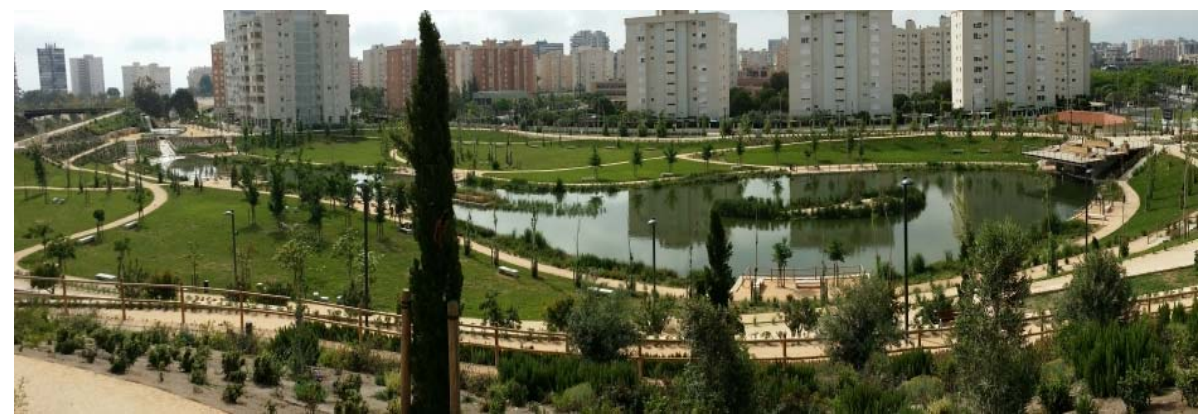

Figure 3: Alicante flooding park, Spain. (Source: Aguas de Alicante, 2018 [13].) 
The volume of rainwater that can be recovered is important and can reach values similar to reclaimed water for urban uses. In the case of the city of Alicante, the water reused at the storm water deposit of San Gabriel reached in 2012 the figure of $454,383 \mathrm{~m}^{3}$, while reclaimed water only slightly exceeded that figure in the same year: $515,182 \mathrm{~m}^{3}$ [14].

The smart city, therefore, must implement the appropriate technological solutions so that the drainage of the city is efficient, and so that the most polluted rainwater can be treated before it reaches the water courses or the sea, and eventually have a proper use. This maximizes environmental sustainability objectives and provides an additional resource especially in water stressed areas.

From a governance perspective, in order to achieve these objectives is essential to integrate water management in urban planning; zoning law and regulations should establish maps of risks and norms that prevent from building in flood zones and impose corrective measures in case the developments are likely to be authorized. Urban planning can determine the uses of the soil, directing growth to non-flood zones, and forcing the construction of sustainable urban drainage systems and networks to minimize flood risks and take advantage of rainwater for new uses.

\section{TRANSPARENCY AND ACCOUNTABILITY}

Transparency and accountability are key issues in the regulatory framework that should govern smart water management. Current technologies allow citizens to have full access to public information from their own homes at every time and the whole year through. This circumstance is fundamental since the disclosure of public information is easier and can be offered without anyone's request. Such situation clearly overcomes the traditional forms of granting access to public information at the citizen's request and through written applications. The challenge now is to ensure that this information, essential for effective public participation, is available in an accessible, simple, complete manner, and also includes information that can be considered "sensitive" for the public authorities (open government).

In the water sector, citizens demand information on tariffs, contracts, choice of suppliers and costs, quality of water supplied, quality of service, among other aspects. This transparency is a key factor in the right to access to water and sanitation. The citizen must have access to the performance and quality indicators of the drinking water they receive [15]. The right to get information, both at the citizen's request or at the Administration's own initiative has only been expressly recognized in Spain by means of the Act 43/2010, December 30th, that regulates the postal service. Such declaration cannot be found in the rest of liberalized public services' legal frameworks such as electricity, oil and telecommunications. Nor this right is expressly declared in the pieces of legislation governing regional and municipal public services such as drinking water supply or wastewater treatment. That omission is even more serious in cases where urban water supply is granted to a concession holder, since the Act 19/2013, December 9th, of transparency, access to public information and good governance, does not force public utility companies to disclose information at the citizen's request. Such companies do not even bear with the obligation to subject their activities to the guiding principles of active and passive transparency. They only have the obligation to provide information to the Administration that owns the service at its request, which force citizens to apply for that information before the regulator instead of making it before the operator [16].

This means that a citizen who wants to know data about the quality of the urban drinking water supply should address the application before the Administration (usually the City Council), which in turn shall therefore have to request the information from the operator. The citizen is not expected to immediately get such information while applying directly for it 
before the company, unless the company has voluntarily accepted such obligation; on the other hand, the company is not obliged to publish sensitive information about the service at his own initiative, neither on its website nor on the social media. This legal framework clearly leave room for improvement, since these companies, although private, manage public services of general interest for all citizens, are benefited with public funds, and can charge citizens fees for the exclusive provision of an essential service. In sum, the general interest involved in this activity, and the public ownership on the service certainly justify these companies should bear with the obligation to provide relevant information on the service both, actively and passively. Therefore, they should be subject to the transparency legislation, regardless of their private nature.

As part of the process to reform and update Directive 98/83/EC on the quality of water intended for human consumption, the College of Commissioners announced the decision to improve water quality as a result of the initiative: Right2Water. The Commission's proposal was presented on February 1st, 2018. Among the new provisions that contain the proposal there is an express obligation for water suppliers to give consumers clear information about the service. On the other hand, consumers are granted the right to get online access to information on the quality and safety of their tap water, as well as to get clear and simple water bills. In addition, the greater access to information about the quality of the service is expected to favour the lower use of bottled water, and therefore, a lower generation of waste [17].

\section{CONCLUSIONS}

Water in the smart city should be approached from an integral perspective, considering the different phases of urban supply, from the capture of water to its delivery to the end user, as well as during the wastewater treatment and reuse stages. The purification and eventual use of storm water and flood management should also be put into consideration.

It is essential to design a regulatory framework that ensures all citizens full access to drinking water in conditions of continuity and good quality, as well as at an affordable price. This regulatory framework should clearly establish the rights and obligations of all the actors, including the Administration responsible for the service, the users, and the private operators that carry out the activity in public-private partnership models.

Along with the regulation, it is important that in the cases of public-private collaboration in the provision of the service, the contractual obligations are clearly set in the contractual documents, including investment commitments, adequate monitoring of networks to avoid leakages, smart metering, as well as any other technological solutions that may be available.

Under an integrated water management approach, water governance should not be limited to ensuring drinking water supply but should extend to an efficient management of wastewater. It is essential in terms of environmental sustainability that wastewater is treated according to regulations, but the smart city must move forward developing solutions that allow new uses for these resources. Giving wastewater a second use results in less pollution emitted to the sea or river courses, and it also represents fewer impacts on natural water sources in accordance with the postulates of the circular economy. The application of tertiary treatment technologies allows getting flows that are perfectly viable for garden irrigation, street cleaning, among other urban uses. Public authorities should promote the implementation of these technologies in the smart city.

On the other hand, there are technical solutions of the greatest interest for the proper management of storm waters. These resources can be deposited, treated and reused, which provides the city with new resources and reduces the pollution caused by storm waters (especially the first rain, whose polluting load is particularly high). The implementation of 
sustainable urban drainage systems also helps to reduce the effects of floods. These infrastructures, combined with an intelligent planning of the territory, which prevents urban uses such as residences in flood zones, can reduce the undesirable effects of these events.

Finally, it is necessary to ensure that all public and private actors act with full transparency and are fully accountable from their actions. Granting the citizens full access to information is an essential tool so they can participate in the decision-making processes and eventually monitor the functioning of services. It is essential to go from "open data" to "open government" in this area, extending transparency obligations to private companies that operate in the different stages of urban supply, wastewater treatment and reuse.

\section{ACKNOWLEDGEMENT}

LIFE project LIFE15 ENV/ES/000598 "Development of an efficient and sustainable metodology for emerging pollutants removal in WWTPs" (1/09/2016-31/08/2019).

\section{REFERENCES}

[1] Smart cities and Communities - European Innovation Partnership, 4701. http://ec.europa.eu/eip/smartcities/files/ec_communication_scc.pdf. Accessed on: 15 Dec. 2017.

[2] General Directorate for internal policies of the European Parliament, Jan. 2014.

[3] Villarejo, H., Smart cities: una apuesta de la Unión Europea para mejorar los servicios públicos urbanos. Revista de Estudios Europeos, 66, pp. 25-51, 2015.

[4] Kirchherr, J., Reike, D. \& Hekkert, M., Conceptualizing the circular economy: An analysis of 114 definitions. Resources, Conservation and Recycling, 127, pp. 221-232, 2017.

[5] Gil Olcina, A. \& Rico Amorós, A., Consorcio de aguas de la Marina Baja. Gestión convenida, integral y sostenible del agua, Servicio de Publicaciones de la Universidad de Alicante: San Vicente del Raspeig, pp. 1-327, 2015.

[6] Molina, A., Permutas de agua natural y agua regenerada. Un modelo de aprovechamiento integral en entornos de escasez. Mercado de derechos al uso privativo de las Aguas en España. Su papel en la gestión de cuencas deficitarias, eds T.M. Navarro \& T.M. Aranzadi, Pamplona, pp. 213-250, 2018.

[7] Melgarejo-Moreno, J. \& Molina-Giménez, A., La Mancomunidad de los Canales del Taibilla en la Provincia de Alicante, MCT, Mancomunidad de los Canales del Taibilla e IUACA, Instituto Universitario del Agua y de las Ciencias Ambientales: Alicante, pp. 1-279, 2017.

[8] Molina, A., El servicio público de abastecimiento de agua en poblaciones. El contexto liberalizador. Tirant lo Blanch, Valencia, pp. 1-489, 2001

[9] Prats, D., Personal communication, 2 Feb. 2018, Data on the destination of purified water in the Province of Alicante, provided by EPSAR (Public Wastewater Treatment Authority of the Valencian Region). Provincial Council of Alicante: Alicante, ES.

[10] Lucas, R., Earl, E.R., Babatunde, A.O. \& Bockelmann-Evans, B.N., Constructed wetlands for stormwater management in the UK: a concise review. Civil Engineering and Environmental Systems, 0(0), pp. 1-18, 2014.

[11] Trapote, A., Gestión de las aguas pluviales en entornos urbanos mediante técnicas de Drenaje Sostenible. Journal of Engineering and Technology, 5(2), pp. 26-40, 2016.

[12] Beltrá, M., Ferrando, J.A. \& Domínguez, C., Parque urbano inundable "La Marjal", Alicante. Equipamiento y servicios municipales, 172, pp. 6-16, 2015.

[13] Aguas de Alicante. http://www.aguasdealicante.es/VisitaParqueLaMarjal. Accessed on: 6 Feb. 2018. 
[14] Morote, A. \& Hernández, M., El uso de aguas pluviales y de tormenta en la ciudad de Alicante. De riesgo a recurso hídrico alternativo. Proceedings of the $X V$ Coloquio Ibérico de Geografia, Murcia, 2015. https://rua.ua.es/dspace/bitstream/10045/ 61721/1/2016_Morote_Hernandez_XV-Coloquio-IbericoGeografia.pdf. Accessed on: 2 Feb. 2018.

[15] Frérot, A., Economía circular y eficacia en el uso de los recursos: un motor de crecimiento económico para Europa. Cuestión de Europa. Fondation Robert Schuman, 331, 2014. https://www.robert-schuman.eu/es/doc/questions-d-europe/qe-331-es.pdf. Accessed on: 31 Jan. 2018.

[16] Blanes, M.A., La transparencia informativa de las Administraciones Públicas, Aranzadi: Pamplona, 2014.

[17] EU-COM. http://europa.eu/rapid/press-release_SPEECH-18-584_en.htm. Accessed on: 4 Feb. 2018. 